\title{
Dissolution, Precipitation, and Deposition of Aluminum- Containing Phases in Tank Wastes
}

(Project Number: 65411)

\section{Principal Investigator}

Jun Liu

Pacific Northwest National Laboratory

P.O. Box 999, MSIN K2-44

Richland, WA 99352

(509) 375-2616 (phone)

(509) 375-2186 (fax)

jun.liu@pnl.gov

Co-Investigator

David Hobbs

Savannah River Technology Center

Aiken, SC 29808

(803) 725-2838 (phone)

(803) 725-4704 (fax)

david.hobbs@srs.gov

\section{University Collaborator}

Dan. Dabbs, Professor Ilhan Aksay

Princeton University, Princeton Materials Institute

Princeton, NJ 08580-5211

(609) 258-1572 (phone)

(609) 258-6878 (fax)

\section{Other Contributors}

Xiaoyi Gong (PNNL)

Larry A. Pederson (PNNL)

Zimin Nie (PNNL)

Morris X. Qian (PNNL)

Norton McDuffie (PNNL consultant) 


\section{Research Objective}

The goal of the proposed work is to understand the kinetics of dissolution, precipitation, and scale formation involving aluminum-containing phases in alkaline salt solutions representative of tank wastes. This research will identify aluminum-containing phases that are likely be present or to form and will predict conditions under which such phases are likely to form or be present. Experiments will identify processing conditions that either promote or inhibit the heterogeneous or homogeneous nucleation and growth of aluminum-containing phases to form precipitates or scales. Test conditions encompass conditions anticipated for waste storage, washing, leaching, concentration in evaporators, and contact with pipes, ion exchangers, and other processing media.

\section{Research Progress and Implications}

Aluminum is one of the principal elements in alkaline nuclear wastes stored at DOE sites, including Hanford and Savannah River. Two of most widely observed phases are gibbsite and boehmite. From the viewpoint of tank waste processing, the dissolution kinetics of gibbsite and boehmite are different, and the slow dissolution phase, boehmite, is more of a concern than gibbsite. It is important to understand when and under what conditions gibbsite and boehmite form in the tank waste and how easy it is for the gibbsite to transform into boehmite.

The hydrothermal stability of gibbsite and boehmite was studied in alkaline solutions ( 2 or $3 \mathrm{M} \mathrm{NaOH})$. The following conclusions have been reached:

- Boehmite is always the stable phase. Gibbsite tends to transform to boehmite.

- Two fundamental mechanisms were identified for hydrothermal transformation of gibbsite to boehmite:

- Dissolution of gibbsite and precipitation of boehmite in the solution. The dissolution and precipitation occurred when the reaction was carried out in a sealed container. Gibbsite was dissolved along (001) planes. Boehmite nucleated from the solution. Further dissolution of gibbsite and growth of boehmite created well-defined, plate-like boehmite particles. In this mechanism, the size and shape of the final boehmite particles are not related to the original gibbsite particles.

- Dehydration of gibbsite and in situ nucleation of boehmite on gibbsite. If the reaction was carried out in an unsealed container, the formation of boehmite followed a different pathway. Gibbsite particles were dehydrated from the (001) planes. Randomly oriented boehmite nucleated on the external and the newly created (001) surfaces. Finally, coagulation of boehmite particles produced fibrous boehmite particles. In this mechanism, the final particle sizes are constrained by sizes of the original gibbsite particles. 
- When an organic aluminum precursor, aluminum alkoxide, was used, bayerite was formed initially. However, bayerite was eventually transformed to boehmite.

- The transformation to boehmite was rapid. Normally, an initial incubation time was observed during which period no boehmite was formed. When the boehmite began to nucleate, the transformation usually was completed within one hour.

- The existence of high concentration of single and multi-salts, such as $\mathrm{NaNO}_{3}, \mathrm{Fe}\left(\mathrm{NO}_{3}\right)_{3}$, etc., gave rise to a longer incubation time but did not change the general behavior for the transformation into boehmite.

\section{Implications}

These results suggest that most aluminum-containing phases in tank wastes will be boehmite. This clearly underlines the importance of boehmite particles in the dissolution behavior of the tank waste as well as the colloidal properties of the sludge. Most likely, both mechanisms contributed to the formation of boehmite in tank wastes. The direct transformation of gibbsite to boehmite in the unsealed container may mimic the tank waste condition. However, the tank wastes have aged for many years, giving more crystalline particles with similar particle sizes. Direct dissolution and precipitation were also possible, which would give large crystalline boehmite particles. To predict the efficiency of the tank waste processing (washing and leaching) and the flow properties, the behavior of the dominant boehmite phases must be understood.

\section{Planned Activities}

PNNL will collaborate with Savannah River Technology Center and with Albert Hu (CH2M Hill Inc.) to study the solubility boundaries and the associated chemical phases and specifications. The results obtained will be used directly in a semi-empirical approach to calculate the critical flow velocity needed to transfer the tank waste across the pipelines.

\section{Publication}

Liu J GJ Lumetta, JW Virden, GL Graff, and NG Colton. 1999. "Characterization of colloidal phases in tank wastes." Proceedings of American Ceramic Society. 